\title{
DISPOSITIVOS MÓVEIS NA EDUCAÇÃO: REFLEXÕES A PARTIR DE PESQUISAS NO CONTEXTO ESCOLAR
}

\section{MOBILE DEVICES IN EDUCATION: REFLECTIONS FROM RESEARCH IN THE SCHOOL CONTEXT}

\section{Maiara dos Santos Dassoler ${ }^{1}$ \\ Graziela Fátima Giacomazzo}

\begin{abstract}
RESUMO: Este artigo buscou analisar como os dispositivos móveis estão sendo inseridos nos processos de ensino e aprendizagem no contexto escolar. Nesse sentido, metodologicamente, a pesquisa se caracteriza como qualitativa e de caráter exploratório, pois realizou-se a partir de um levantamento bibliográfico de publicações científicas desta área nos últimos cinco anos, disponíveis em bases de dados como ScIELO, Google Acadêmico e Oasisbr. Foram determinados critérios para as escolhas destes artigos, portanto, deveriam responder ao nível de ensino; se a pesquisa foi realizada em uma escola pública ou privada; quais os programas ou aplicativos mais utilizados; quais os conteúdos que foram trabalhados com essas tecnologias; as contribuições pedagógicas que as tecnologias móveis propiciam; e o papel do professor no processo de ensino e aprendizagem com apoio das tecnologias móveis. Dessa forma, a partir das análises, pode-se constatar que existem poucas pesquisas acerca deste assunto na educação básica. Além disso, com os resultados obtidos, foi possível apontar as possibilidades pedagógicas que o uso dos dispositivos móveis pode proporcionar como ferramenta nos processos educativos.
\end{abstract}

PAlavras Chave: Dispositivos Móveis. Ensino e Aprendizagem. Possibilidades Pedagógicas.

\begin{abstract}
This article sought to analyze how the mobile devices are being inserted in the processes of teaching and learning in the school context. In this sense, methodologically, the research is characterized as qualitative and exploratory, since it was carried out from a bibliographical survey of scientific publications of this area of the last five years, available in databases such as ScIELO, Google Academic and Oasisbr. Criteria for the choices of these articles were determined, therefore, they should respond to the level of education; whether the research was conducted in a public or private school; which programs or applications are most used; what contents have been worked with these technologies; the pedagogical contributions that mobile technologies provide; and the role of teachers in the teaching and learning process
\end{abstract}

\footnotetext{
${ }^{1}$ Acadêmica do Curso de Pedagogia-UNESC. mays2dassoler@ hotmail.com

2 Doutora em Educação, Docente no Curso de Pedagogia e PPGE- UNESC. gfg@unesc.net.
} 
supported by mobile technologies. Thus, from the analysis, it can be verified that there is little research on this subject in basic education. In addition, with the results obtained, it was possible to point out the pedagogical possibilities that the use of mobile devices can provide as a tool in educational processes.

KEYWORDS: Mobile Devices. Teaching and Learning. Pedagogical Possibilities.

\section{INTRODUÇÃO}

A intensa propagação das Tecnologias da Comunicação e Informação (TIC) ocorreram de maneira muito significativa desde o final do século $\mathrm{XX}$ e possibilitaram inovações nas formas de transmitir, informar, comunicar e também de "fazer". Atualmente, grande parte da população, de diversas faixas etárias, por intermédio do uso das redes e dos dispositivos móveis ${ }^{3}$ como: smartphones, tablets, notebooks, laptops, entre outros, são capazes de se conectarem e compartilharem suas experiências, constituindo um novo estilo de vida.

Nessa perspectiva, entende-se que as tecnologias móveis podem ser introduzidas no espaço escolar, principalmente pela sua acessibilidade e mobilidade. Por conseguinte, verifica-se nos ambientes escolares que a maioria dos alunos possui algum tipo de tecnologia móvel, especialmente os smartphones. Além do fácil acesso, segundo Kenski (2012, p. 44), “a presença de uma determinada tecnologia pode induzir profundas mudanças na maneira de organizar o ensino." Tendo em vista essa premissa, entende-se a importância de discutir este tema para que se possa refletir e considerar alternativas de ensino e aprendizagem com o uso dessas tecnologias.

A integração das tecnologias móveis nos processos pedagógicos é denominada por "aprendizagem móvel" ou "aprendizagem com mobilidade", mais conhecida por seu termo inglês Mobile Learning ou M-Learning. Ela contribui com novas práticas pedagógicas, não convencionais, sendo um desafio para o professor ao ter que associar essas tecnologias à educação contemporânea.

\footnotetext{
${ }^{3}$ Um dispositivo móvel é um aparato de computação portátil, pequeno, geralmente equipado com um método de entrada e uma tela de exibição (tela sensível ao toque ou um mini teclado). (CANTO, 2018, p. 10).
}

Saberes Pedagógicos, Criciúma, v. 3, n², julho/dezembro 2019.- Curso de Pedagogia - UNESC 
O interesse por este tema, tecnologias móveis, surgiu após uma matéria ser transmitida no programa de televisão Globo Repórter, que faz parte da emissora Rede Globo. A matéria, que foi realizada na cidade de Araranguá (SC), relatou a história de uma professora de Geografia da rede Estadual de ensino desse município e sua relação com as tecnologias, mais especificamente com o smartphone. Neste caso, a professora constatou nas aulas que todos seus alunos possuíam este dispositivo móvel e, para compensar a falta dos livros didáticos, ela, com auxílio dos estudantes, criou um aplicativo com todas as informações sobre a Europa, encurtando as fronteiras entre o velho continente e a cidade habitada por eles.

Diante disto, esta temática, após muitas indagações, suscitou o seguinte problema: como os dispositivos móveis estão sendo inseridos nos processos educativos em instituições de ensino básico? Atendendo a esta problemática, a pesquisa propõe como objetivo geral: analisar por meio de publicações científicas, como os dispositivos móveis estão sendo inseridos nos processos educativos em instituições de ensino básico.

Nesse sentido, tem-se como objetivos específicos: identificar em qual nível de ensino os dispositivos móveis são mais utilizados; verificar se o uso dos dispositivos nos processos educativos ocorre em escolas públicas ou privadas; reconhecer se as experiências com o uso dos dispositivos móveis são interdisciplinares; identificar quais são os dispositivos e seus aplicativos/programas utilizados nos processos de ensino e aprendizagem; reconhecer as contribuições pedagógicas com o uso de dispositivos móveis nos processos educativos e, por fim, compreender o papel do professor em relação ao uso dos dispositivos móveis nos processos educativos.

Esta pesquisa vincula-se, no Curso de Pedagogia, à linha de pesquisa Teoria e Prática Pedagógica, no eixo temático Tecnologias Aplicadas à Educação. Este estudo espera contribuir para a reflexão, tanto dos educadores quanto dos educandos, sobre as possibilidades pedagógicas que o uso de dispositivos móveis pode promover dentro de uma sala de aula. Além disso, elucidar novas experiências de ensino-aprendizagem que essas tecnologias podem proporcionar. 


\section{TECNOLOGIAS: CONTEXTO HISTÓRICO}

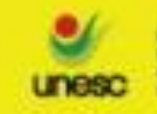

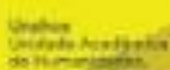
.

A relação entre homem e natureza sempre foi marcada pela tecnologia, que, segundo Blanco e Silva (1993), vem da palavra technê, que significa (arte ou ofício) e logos que é o (estudo de). Para Kenski (2003), a tecnologia esteve presente nas mais distantes sociedades durante a evolução da humanidade. Um exemplo disso são as invenções que perpetuaram nosso contex to histórico, como a descoberta do fogo ou a criação da roda. Essas e outras conquistas, consideradas tecnologias, provocaram impactantes mudanças no âmbito social, sobretudo na economia, na política e também na divisão do trabalho.

Ainda, conforme Blanco e Silva (1993), ao longo de muitos anos, a tecnologia ficou vinculada a termos técnicos, como máquinas, operações de ofícios, utensílios, entre outros. Porém, afastou-se de um caráter descritivo e enumerativo nos princípios do século XVIII, em que o saber técnico e o saber intelectual passam a ser vistos sem dicotomia. Neste caso, a tecnologia começa a se comprometer também com experimentos, verificação, comprovação de dados e teorias.

Em vista disso, a partir do século XX, alguns campos da tecnologia apresentaram grande destaque, especialmente o das tecnologias de informação e comunicação (TIC). Essas tecnologias objetivam a transmissão de informações de uma maneira rápida e eficiente, por meio das telecomunicações e pela internet. No que diz respeito às indústrias, as novas tecnologias vieram para alavancar a produção e por isso muitas empresas investem significativamente nesse mercado.

Para Castells (2003), o surgimento das TIC é caracterizado pelo seu alcance global, pela integração de todos os meios de comunicação e pela interatividade, que está mudando e mudará para sempre a cultura. Em conformidade, Lemos (2004, p. 1) salienta que "as novas tecnologias de comunicação e informação estão reconfigurando os espaços urbanos, bem como as práticas sociais destes mesmos espaços". Dessa forma, percebe-se que se vive em uma era de grande expansão tecnológica, também denominada de "sociedade da informação", pois as grandes transformações que estão ocorrendo no momento envolvem as tecnologias, principalmente as TIC.

Saberes Pedagógicos, Criciúma, v. 3, n², julho/dezembro 2019.- Curso de Pedagogia - UNESC 


\subsection{O uso das TIC na Educação}

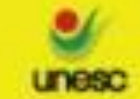

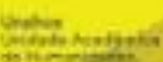

No campo da educação, as Tecnologias da Informação e Comunicação têm possibilitado diversas formas de ensinar e aprender. No Brasil, de acordo com a pesquisa TIC Educação (CGI.br, 2016), o processo de inclusão das tecnologias teve início em 1970. Nesta década foram realizadas as primeiras experiências com uso de computadores em escolas, sendo que o projeto vigente na atualidade é o ProInfo.

O ProInfo é visto como a principal política nacional de tecnologia educacional do país. O objetivo do projeto é promover o uso pedagógico da informática na rede pública de educação básica. De acordo com Almeida e Valente (2016), no Proinfo foram criadas duas ações que aconteceram em conjunto: a implantação de laboratórios de informática nas escolas e a formação de professores em todas as áreas disciplinares, para que utilizassem as tecnologias como ferramenta exclusivamente pedagógica nas atividades em sala de aula.

Após vinte (20) anos, desde a criação do programa ProInfo no Brasil, a última atualização das políticas públicas, envolvendo a tecnologia educacional, foi no ano de 2007, com o ProInfo Integrado. De acordo com o Ministério da Educação (MEC), “o ProInfo Integrado é um programa de formação voltada para o uso didático-pedagógico das Tecnologias da Informação e Comunicação (TIC) no cotidiano escolar.” (BRASIL, 2018). Segundo Almeida e Valente (2016), a intenção deste programa era de integrar as TIC às atividades que aconteciam na escola, especificamente na sala de aula. No ProInfo Integrado, algumas ações foram criadas como PBLE: Programa de Banda Larga na Escola - UCA: Projeto um computador por aluno - Distribuição de tablets.

A seguir apresenta-se na Figura 1, o histórico desses projetos:

Saberes Pedagógicos, Criciúma, v. 3, n², julho/dezembro 2019.- Curso de Pedagogia - UNESC 
Figura 1: Histórico dos Projetos e Políticas Públicas

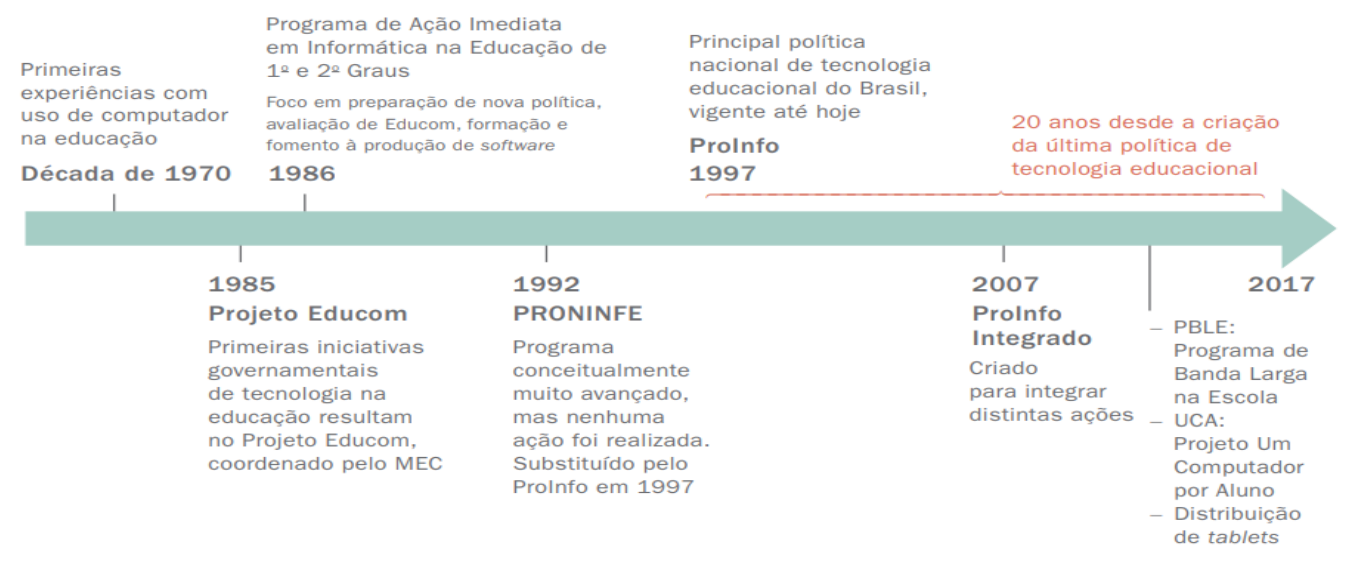

Fonte: CGI.br (2016, p.34)

Embora os debates e programas realizados acerca da educação e tecnologia já venham sendo executados há anos no Brasil, ainda se verifica a utilização dos recursos tecnológicos de modo muito inseguro no cenário educacional atual. De acordo com Almeida e Valente (2016), para que aconteça a implantação efetiva das tecnologias na educação, algumas mudanças devem ser realizadas, como nas políticas públicas, nas crenças, nos valores e concepções. Para isto, exige-se um grande esforço dos educadores, gestores e da sociedade de maneira geral.

Nesse seguimento, para Moran (2000), educar com novas tecnologias é um desafio que até agora não foi enfrentado com profundidade, pois são feitas apenas adaptações e pequenas mudanças. Além disso, Moran (2000) aponta que o ensinar utilizando as tecnologias só será de fato revolucionário se o ensino que ainda persiste, no qual professores e alunos permanecem distantes entre si, for modificado. "Caso contrário, conseguiremos dar um verniz de modernidade, sem mexer no essencial." (MORAN, 2000, p. 63). Na opinião de Kenski (2003), essas tecnologias não estão restritas em apenas informar, mas também formar, pois a utilização das TIC interfere na maneira de pensar, agir, sentir, de se relacionar, de adquirir conhecimento, ou seja, cria-se uma nova cultura social. Em consonância com estas ideias, um dos aspectos importantes a se destacar em relação à integração das TIC na educação é a maneira com que essas tecnologias serão inseridas nas instituições, sobretudo no 

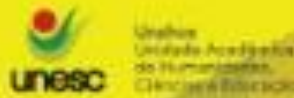

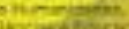

planejamento do professor, para que se torne um recurso de grandes significados e enriqueça as atividades no processo de ensino e aprendizado.

Partindo disso, com a possibilidade de utilização dessas tecnologias nos processos de ensino e aprendizagem, os documentos que norteiam a educação passam a reconhecer que essas ferramentas podem ser de grande magnitude no desenvolvimento de habilidades. Deste modo, em 20 de dezembro de 2017 foi homologada a Base Nacional Comum Curricular (BNCC). Nela, foram definidas as competências que deverão ser realizadas nas escolas públicas e privadas a partir de 2019. Entre essas competências, duas deram ênfase às tecnologias na escola. A competência de número 4 (quatro), que prevê o uso de diferentes linguagens, incluindo a digital, e a competência de número 5 (cinco), que determina a utilização e a criação de tecnologias digitais de forma crítica, significativa, reflexiva e ética (BRASIL, 2017).

Dessa forma, a Base Nacional Comum Curricular (BNCC) entende que o aluno não é somente o receptor de conteúdos e o professor o detentor do saber (Freire, 2005). Além disso, o uso de quadro, giz, cadernos, entre outros, também não serão os únicos recursos disponíveis no processo de ensino e aprendizagem. As tecnologias também passam a ser consideradas como instrumentos nas propostas pedagógicas, tanto de escolas públicas, quanto de escolas privadas, objetivando que a partir de seu uso o aluno seja capaz de desenvolver novas competências as quais o contexto atual exige.

Outrossim, segundo a pesquisa TIC Educação (CGI.br, 2016, p. 60), deseja-se que as mudanças conduzidas pela Base Nacional Comum Curricular (BNCC) provoquem o interesse dos jovens perante a escola. Assim, um dos caminhos é que o professor adote novas práticas pedagógicas apoiadas em novas tecnologias. Por meio delas, conforme Mercado (2002), o educador terá possibilidades de realizar práticas, estimulando o trabalho em grupo ou individual. Além disso, o professor neste contexto tem a oportunidade de executar projetos interdisciplinares, independentemente de estar dentro ou fora da sala de aula, pois algumas dessas tecnologias fornecem mobilidade, em razão de serem dispositivos móveis. 


\section{SABERES PEDAGÓGICOS}

Revista do Curso de Graduaçăo de Pedagogia - Unesc

ISSN 2526-4559

\section{DISPOSITIVOS MÓVEIS NA EDUCAÇÃO}

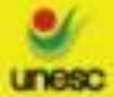

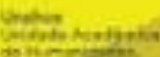

Dispositivos móveis são considerados aparelhos de comunicação sem fio e de capacidade limitada em relação à computacional. Além disso, usam a bateria como fonte de alimentação (MORAIS et al, 2011). Um dos seus principais atrativos é seu custo, relativamente inferior ao de outras tecnologias e a já citada mobilidade, pois, por ser uma comunicação sem fio, pode ser transportada para qualquer ambiente. De acordo com Nascimento (2016, p. 25), os dispositivos móveis "potencializam a colaboração entre os usuários que podem produzir, compartilhar, editar materiais e dialogar de forma síncrona ou assíncrona."

Ainda, conforme a Unesco (2014), existem hoje no mercado inúmeras tecnologias móveis e elas estão em constante evolução, mas consideram-se dispositivos móveis os telefones celulares (smartphones), leitores de livros digitais como (e-readers), tablets, consoles manuais de videogames e aparelhos portáteis de áudio. Segundo a Unesco (2014), os mais utilizados pelos educadores e estudantes sem dúvidas são os smartphones e tablets e isso se deve pela facilidade de acessar informações e compartilhá-las.

Nesse sentindo, pesquisas realizadas comprovam essa preferência, pois, de acordo com IBGE (2016), de toda a população brasileira, cerca de $64,7 \%$ dela já tem o acesso à internet, ou seja, aproximadamente 116 milhões de pessoas no Brasil estão conectadas. A pesquisa afirma que para o acesso à internet são utilizados dispositivos móveis, e que o celular continua ganhando destaque por ser o mais manipulado.

Em 2016, foi lançada a segunda edição da pesquisa Juventude Conectada, idealizada pela Fundação Telefônica Vivo e realizada em parceria com o Ibope Inteligência e com o Instituto Paulo Montenegro. Foram entrevistados cerca de 1.440 jovens por todo o território nacional no ano de 2015. A pesquisa destacou que $85 \%$ dos entrevistados usam o celular como principal dispositivo de acesso à internet, apontando assim um crescimento de 102\% em relação à primeira edição do estudo, realizada em 2013.

No contexto educacional, foi efetuada, também em 2016, uma investigação sobre a utilização de celulares em atividades escolares. De acordo com a pesquisa TIC Educação (CGI.br, 2016), o uso desse tipo de dispositivo foi citado por 52\% dos alunos de turmas de 5o

Saberes Pedagógicos, Criciúma, v. 3, n² , julho/dezembro 2019.- Curso de Pedagogia - UNESC 


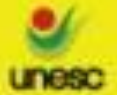

ationient
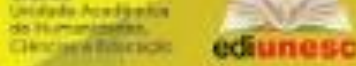

ano e 9o ano do Ensino Fundamental e/ou 2o ano do Ensino Médio, localizadas em áreas urbanas.

Dessa forma, o cenário atual deixa evidente que os aparelhos móveis são parte integrante do cotidiano moderno de muitas pessoas, em diferentes idades. Em relação às atividades preferidas entre os jovens, destacam-se a utilização das redes sociais, grupos de conversas, jogos por aplicativos, vídeos do YouTube, verificação de e-mails e notícias online.

Da mesma maneira, o público infantil também tem interesse nas tecnologias, pois, de acordo com Muller (2014, p.11), crianças que possuem acesso à tecnologia “[...] pedem para fazer uso dela com seus corpos, gestos e falas, que demonstram interesse em assistir a um vídeo no celular, de pesquisar na internet, de mostrar ao adulto o que lhe fascina quando conectadas." Diante do exposto, verifica-se que os dispositivos móveis podem ser utilizados para aprendizagem dos estudantes da educação infantil até o ensino de jovens e adultos.

Partindo disso, em se tratando de uso de tecnologias em espaços escolares, não se deve pensar somente em um lugar fixo, como os laboratórios de informática e utilizando apenas desktop, mais conhecido como computador de mesa. Segundo Oliveira e Medina (2007, p. 3), a tecnologia móvel "[..] permite o acesso a conteúdos educacionais em qualquer lugar e a qualquer hora, aproveitando assim horários livres tais como de espera ou de locomoção." Em concordância com os autores, as diretrizes de políticas para a aprendizagem móvel da Unesco (2014, p. 7), “acredita que as tecnologias móveis podem ampliar e enriquecer oportunidades educacionais para estudantes em diversos ambientes."

Portanto, compreende-se que as tecnologias móveis são capazes de oferecer mobilidade e maior flexibilidade ao sujeito, sendo que ele não necessita de um lugar específico de aprendizagem, uma vez que, na fila de um banco, qualquer estudante pode baixar em seu smartphone um jogo educativo de matemática e resolver questões de raciocínio lógico, por exemplo.

De acordo com a Unesco (2014, p. 11), os dispositivos móveis estão “[...] longe de ser uma possibilidade teórica, a aprendizagem móvel é uma realidade concreta." Ademais, a Unesco (2014) expõe ainda 13 razões para inserir essas tecnologias na educação, entre elas, pode-se enfatizar a melhora da comunicação e da aprendizagem contínua; a aproximação do

Saberes Pedagógicos, Criciúma, v. 3, n², julho/dezembro 2019.- Curso de Pedagogia - UNESC 

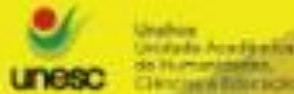

aprendizado formal do informal; a otimização do tempo em sala de aula, que propicia ao aluno aprendizagem em qualquer hora e em qualquer lugar, como supracitado.

À vista disso, as tecnologias móveis permitem tanto ao professor, quanto ao aluno, compartilharem conhecimento de modo instantâneo e em diferentes mídias. Esses compartilhamentos podem ser realizados por intermédio do smartphone, como já mencionado, pois ele é o dispositivo móvel mais utilizado entre os estudantes, já que, atualmente, "se o computador ainda é um objeto restrito, o celular está presente em boa parte das escolas, nas mochilas dos alunos de diferentes classes sociais." (MERIJE, 2012, p. 81).

Porém, muitas instituições ainda impedem o uso de celulares dentro das salas de aulas, como é o caso da França, onde o parlamento aprovou a proibição dos celulares em escolas. Segundo o site G1 (2018), “alunos não poderão mais usar aparelhos ligados à internet em todo o espaço escolar. Lei é classificada pelo governo de 'medida de desintoxicação' contra a distração nas salas de aula.” Entretanto, haverá exceções para o uso pedagógico e também para crianças e adolescentes com algum tipo de deficiência. No território brasileiro, alguns estados também condenam o uso do celular dentro das escolas, como é o caso de Santa Catarina. Conforme a lei $\mathrm{n}^{\mathrm{o}} 14.363$, de 25 de janeiro de $2008^{4}$, "fica proibido o uso de telefone celular nas salas de aula das escolas públicas e privadas no Estado de Santa Catarina." (SANTA CATARINA, 2008).

Uma das características que torna o uso do celular proibido em muitas escolas é o fato da dispersão da concentração (ZUIN; ZUIN, 2018), como conversas ao telefone, jogos, envio de mensagens, redes sociais e acesso a diferentes sites. Além disso, existem também, na opinião da autora Dias (2012), as limitações pedagógicas. Segundo ela, as tecnologias móveis possuem espaço de visualização restrito, fragmentação de conteúdos, pouco conhecimento por parte dos educadores e, por fim, o uso da tecnologia como suporte e não como uma ferramenta. Desta forma, quando se fala na utilização de dispositivos móveis na educação, em particular os smartphones, as opiniões se dividem, caracterizando um assunto polêmico.

Se os smartphones são vistos com restrições negativas nas propostas pedagógicas, os tablets, diferentemente, ganham espaço nas escolas públicas e privadas há

\footnotetext{
${ }^{4}$ Existe o Projeto de Lei 0198.8/2016, do deputado estadual Antonio Aguiar (PMDB) que altera a lei n. 14.636/2008, que proíbe uso de telefone celular nas escolas de Santa Catarina. O projeto autoriza o uso para fins pedagógicos. Mais informações: http://www.alesc.sc.gov.br/legislativo/tramitacao-de-materia/PL./0198.8/2016.

Saberes Pedagógicos, Criciúma, v. 3, n² , julho/dezembro 2019.- Curso de Pedagogia - UNESC
} 

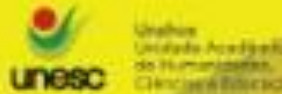

algum tempo. Isso acontece desde a segunda etapa do Proinfo integrado, que ocorreu de 2007 a 2016, onde foram distribuídos dispositivos tecnológicos para uso em sala de aula, como quadros interativos, desktops, laptops e os tablets. De acordo com TIC Educação (CGI.br, 2016), a presença dos tablets em escolas públicas e privadas na pesquisa de 2012 eram de $2 \%$ e $7 \%$ respectivamente, porém, em 2016, passaram para $32 \%$ nas públicas e $36 \%$ em instituições privadas. Contudo, há muitas críticas em relação a essa política de distribuição dos tablets conforme pesquisa realizada por Giacomazzo e Fiuza (2014).

Mesmo com o crescimento nas pesquisas, observa-se, ainda, alguns obstáculos envolvendo essa tecnologia móvel na aprendizagem segundo Giacomazzo e Fiuza (2014), a começar pela precariedade do acesso à internet nas instituições brasileiras, sobretudo nas públicas, até mesmo a falta de formação dos professores para manusearem as novas tecnologias. Desse modo, é de extrema relevância a discussão de temas envolvendo tecnologias, educação e aprendizagem, para que esses aspectos possam ser refletidos, como também, compreender o real potencial pedagógico das tecnologias.

\subsection{Mobile Learning}

O ensino e aprendizagem apoiado em dispositivos móveis se constitui em uma nova modalidade nos processos pedagógicos, a chamada "aprendizagem móvel" ou “aprendizagem com mobilidade", em uma tradução para o inglês significa (Mobile Learning ou m-Learning).

Lehner e Nosekabel (2002) definem m-learning como "qualquer serviço ou facilidade que supre um aprendiz com informação eletrônica em geral e conteúdo educacional que auxilia na aquisição de conhecimento independentemente de espaço e tempo." (apud DIAS; ARAÚJO, 2012, p. 3). Ainda, para Lemos (2009), não se pode dissociar mobilidade, comunicação, espaço e lugar, pois, “[...] comunicar é fazer mover signos, mensagens, informações, sendo toda mídia (dispositivos, ambientes e processos) estratégias para transportar mensagens afetando nossa relação com o espaço e o tempo.” (LEMOS, 2009, p. 28).

Saberes Pedagógicos, Criciúma, v. 3, n², julho/dezembro 2019.- Curso de Pedagogia - UNESC 
Para os autores Rochadel, Aquino e Silva (2012), o mobile learning é considerado como uma nova forma de aprendizagem que nunca acabará. Será um modelo de ensino que pode atender às urgências da aprendizagem, além de propiciar atividades extremamente interativas. Para Assis e Silva (2018, p. 3), “aprendizagem móvel (mobile learning) envolve o uso de tecnologias móveis isoladamente ou combinadas com outras tecnologias viabilizando a aprendizagem ubíqua.” Já na visão de Mülbert (2011), alguns conceitos apresentados sobre de m-learning têm definições tecnocêntricas que estão ligadas somente às tecnologias e não aos sujeitos.

Por essa razão, Mülbert (2011) diz que apesar das tecnologias móveis serem uma tendência na educação contemporânea e que elas podem contribuir para inovações metodológicas, os conceitos sobre mobile learning devem ultrapassar aspectos tecnológicos e dar ênfase também ao ser humano. Pois, para a autora, focar apenas nos dispositivos que proporcionam mobilidade contempla só a metade da importância que o termo aborda.

O m-learning é uma modalidade de ensino que pode ser usada em diferentes situações de ensino e aprendizagem. O docente tem por opção utilizá-lo como um complemento de experiências em sala de aula, até mesmo como parte fundamental de contextos de aprendizagem tradicional. O interessante é não fazer do m-learning uma atividade somente de "lazer", como em pequenos exercícios de uma disciplina específica.

Quadro 1 - Recursos e estratégias de aprendizagem envolvendo as tecnologias móveis

\begin{tabular}{|c|c|}
\hline Videoaulas & $\begin{array}{l}\text { Gravadas em estúdio, geralmente de curta duração, especialmente para consumo } \\
\text { em telas menores e em pequenos intervalos de tempo. O fornecedor pode } \\
\text { disponibilizá-las apenas on-line, o que limita o acesso, ou em modo off-line. }\end{array}$ \\
\hline Aplicativos & $\begin{array}{l}\text { Desenvolvidos sob medida para dispositivos móveis, podem combinar } \\
\text { questionários interativos, conteúdo multimídia e mecanismos de interação entre } \\
\text { os usuários. }\end{array}$ \\
\hline Gamificação & $\begin{array}{l}\text { Jogos digitais completamente voltados à educação, que aproveitam mecanismos } \\
\text { diversos, como personagens, pontuação, prêmios e níveis de dificuldade, a fim de } \\
\text { dinamizar o processo de aprendizagem. }\end{array}$ \\
\hline Livros digitais & $\begin{array}{l}\text { Podem ser simples arquivos estáticos em PDF ou explorar ao máximo os recursos } \\
\text { multimídias disponíveis em dispositivos móveis, incluindo leitura, vídeos, } \\
\text { áudios, etc. }\end{array}$ \\
\hline Cursos e-learning & $\begin{array}{l}\text { Treinamentos desenvolvidos de acordo com padrões de mobilidade, como } \\
\text { adaptação a telas pequenas, que funcionam a partir de ambiente virtual de } \\
\text { aprendizagem também otimizado para mobile. }\end{array}$ \\
\hline
\end{tabular}

Saberes Pedagógicos, Criciúma, v. 3, n², julho/dezembro 2019.- Curso de Pedagogia - UNESC 


\begin{tabular}{|c|l|}
\hline Redes sociais acadêmicas & $\begin{array}{l}\text { Disponíveis em dispositivos móveis por meio de aplicativos, com foco principal } \\
\text { na interação entre os usuários. }\end{array}$ \\
\hline Pesquisas em buscadores & $\begin{array}{l}\text { Busca qualquer informação na rede, apresentando os resultados de uma forma } \\
\text { organizada, rápida e eficiente.Os mais acessados pelos usuários são: Google, } \\
\text { bing, Yahoo. Porém, existem ainda Ask, Blekko, Blippex, Yandex, Baidu, entre } \\
\text { outros. }\end{array}$ \\
\hline
\end{tabular}

Fonte: Adaptado de Edools (2016).

Percebe-se a partir do quadro, que o professor tem a possibilidade de ensinar os alunos em contextos formais e menos formais, por meio de videoaula, jogos educativos, pesquisa em buscadores, entre outros, criando novos horizontes de ensino aprendizagem por meio da interação entre sujeitos, tecnologias e ambientes.

Nesta perspectiva, o papel do professor no processo de ensino e aprendizagem com as tecnologias é fundamental. De acordo com Behrens (2000), o docente deverá auxiliar o aluno a interpretar os dados, a relacioná-los e contextualizá-los. Portanto, a formação continuada desses profissionais será de extrema importância, pois assim o professor será capaz de mediar esses recursos e estratégias de acordo com seu objetivo dentro do planejamento.

\section{METODOLOGIA, APRESENTAÇÃO E ANÁLISE DE DADOS}

O presente trabalho de pesquisa, que tem por tema os dispositivos móveis na educação, pretende analisar, por meio de publicações científicas, como os dispositivos móveis estão sendo inseridos nos processos educativos em instituições de ensino.

No que se refere à natureza, a pesquisa é classificada como básica, já que, de acordo com Pinheiro (2010, p. 19), “a pesquisa básica tem como objetivo gerar conhecimentos novos úteis para o avanço da ciência sem aplicação prática prevista. Envolve verdades e interesses universais."

Quanto à abordagem metodológica, a pesquisa é considerada como qualitativa, pois, conforme Pinheiro (2010, p. 20), “[...] há uma relação dinâmica entre o mundo real e o sujeito, isto é, um vínculo indissociável entre o mundo objetivo e a subjetividade do sujeito que não pode ser traduzido em números. [...] Não requer o uso de métodos e técnicas estatísticas."

Saberes Pedagógicos, Criciúma, v. 3, n², julho/dezembro 2019.- Curso de Pedagogia - UNESC 
Além disso, a pesquisa é de caráter exploratório, pois foi realizada a partir de levantamento bibliográfico. Mattar (2005) afirma que a pesquisa exploratória tem como objetivo promover informações que ampliarão o conhecimento do pesquisador em relação ao tema a ser pesquisado. Ademais, a pesquisa será descritiva, já que, segundo Andrade (2001, p. 124), “[...] os fatos são observados, registrados, analisados, classificados e interpretados, sem que o pesquisador interfira neles."

Em consideração aos procedimentos técnicos, esta pesquisa se constituiu a partir de uma revisão sistemática bibliográfica. De acordo com Gil (2002, p. 44), "A pesquisa bibliográfica é desenvolvida com base em material já elaborado, constituído principalmente de livros e artigos científicos." Por fim, os artigos científicos coletados nas bases de dados deverão ser dos últimos cinco anos, de língua portuguesa. Além disso, necessitam responder aos objetivos específicos desta pesquisa.

Dessa forma, para encontrar as respostas ao problema da pesquisa, os dados foram coletados inicialmente na base SciELO (Scientific Electronic Library Online), no dia 02 de agosto de 2018. Para o refinamento da busca, foram utilizados os termos Dispositivos Móveis e Ensino Fundamental; para concluir, foram aplicados todos os índices. Em relação aos filtros, foram empregados todos que a SciELO possui, que são: coleções, periódico, idioma, ano de publicação, SciELO áreas temáticas, WoS áreas temáticas, citáveis e não citáveis e, por fim, tipo de literatura, todos os artigos encontrados foram desconsiderados.

A segunda busca, que ocorreu nesta mesma data, também se realizou no banco de dados da SciELO e os termos aplicados foram: Educação Básica e Dispositivos Móveis em todos os índices, para refinamento foram empregados todos os filtros que o SciELO possui, como já citados acima. Partindo disso, foram localizados dois artigos, um deles foi o mesmo da pesquisa anterior. Porém, o segundo artigo trata-se de uma coleção do Brasil, do ano de 2015, sendo este o eleito para análise. Adiante, na mesma data e neste mesmo banco de dados, foi efetuada a terceira coleta, porém, todos os artigos encontrados foram exclusos. Desta forma, após as três coletas, verificou-se que apenas um artigo respondeu aos objetivos específicos desta pesquisa, totalizando um artigo do banco de dados SciELO, que tem por autores Santarosa e Conforto (2015).

Além do banco de dados SciELO, foi realizado também no dia 02 de agosto de 
2018 uma pesquisa avançada pelo Google Acadêmico. Para o refinamento foi posto como frase exata: Tecnologias Móveis na Educação, foi selecionado a opção no título do artigo, e com as datas entre 2013 a 2018. Com isso, foram obtidos 13 artigos de língua portuguesa como resultado, porém, para a análise foram escolhidos um artigo de Muller (2015) e um de Lombardi, Rosan e Gitahy (2017). Ainda no Google Acadêmico, outro termo foi utilizado como: Dispositivos Móveis na Educação, com as mesmas filtragens da pesquisa anterior, e de resultado obteve-se 15 artigos de língua portuguesa, entretanto, para análise foram determinados 3. Os autores do primeiro artigo selecionado são Dias, Deus e Ireland (2013), do segundo Gomes (2013) e, por último, Nascimento e Castro Filho (2016).

No dia 06 de agosto de 2018, foi efetuada uma busca avançada no portal brasileiro Oasisbr. Este portal permite o acesso gratuito à produção científica de autores associados a universidades e institutos de pesquisa brasileiros. Para a efetivação da pesquisa, foram utilizados inicialmente os termos: Dispositivos móveis e Educação. Para refinar foi posto artigo como documento e data superior a 2013. Após a conclusão da busca, foi realizada uma segunda filtragem, com o idioma (língua portuguesa) e com assunto (educação), obtiveram-se 4 resultados, para análise foi eleito o artigo de Lima et al. (2014).

Nesta sessão, apresentam-se as análises dos 07 artigos selecionados a partir da revisão de literatura. A análise recai sobre os seguintes aspectos: nível de ensino, se a instituição é pública ou privada, conteúdos trabalhados, tecnologias, aplicativos/programas, contibuições peagógicas e, por fim, o papel dos professores. Esses aspectos foram considerados, pois se relacionam com os objetivos específicos desse trabalho e consequentemente buscam responder o problema de pesquisa.

\subsection{Dispositivos móveis e seu lugar na escola}

Dentre os artigos analisados, foi possível identificar que o nível de ensino é bem diversificado, pois ocorreram pesquisas sobre o uso dos dispositivos móveis desde a educação infantil até o ensino de jovens e adultos. Foram analisados: um artigo da educação infantil, dois do ensino fundamental, sendo um dos anos iniciais e um dos finais. Além disso, obtevese, ainda, dois artigos do ensino médio e dois artigos da EJA para análise. Diante disso, pode-

Saberes Pedagógicos, Criciúma, v. 3, n², julho/dezembro 2019.- Curso de Pedagogia - UNESC 
se inferir que as tecnologias móveis são acessíveis para qualquer idade e o professor tem a possibilidade de inserir e trabalhar com elas em qualquer nível de ensino. Visto que, nos últimos anos, as crianças antes mesmo de chegarem aos centros de educação infantil, estão inseridas na cultura digital, em razão de seus pais já possuírem algum dispositivo de acesso à internet, aplicativos, jogos, entre outros. Ou seja, muitas crianças que frequentam as escolas, atualmente, apresentam uma certa famialiarização em relação as tecnologias.

No que tange aos jovens e os adultos, as tecnologias móveis se fazem presente no dia a dia constantemente. De acordo com a Juventude conectada (2016), oberservou-se um enorme crescimento de jovens em ambientes digitais acessado pelos dispositivos móveis, não só no Brasil, como em outros países, ocasionando uma tendência global. Na grande maioria dos casos, essas tecnologias são conduzidas até as insitutições de ensino.

Neste seguimento, o professor que optar em usar as tecnologias como apoio nos processos de ensino e aprendizagem deve compreender a importância de utilizá-la de maneira coerente, ou seja, ele deve atender às especificidades dos alunos em cada idade. Ademais, segundo Behrens (2000), o docente deve estabelecer quais os objetivos pretende atingir com determinada tecnologia.

Além do nível de ensino, foi investigado, também, se as instituições que utilizam as tecnologias móveis eram em sua maioria privadas ou públicas. Desta forma, verificou-se que dos sete artigos analisados, seis foram de escolas públicas. Entre eles, destaca-se um artigo que aborda uma situação em uma escola pública federal. Quanto à escola privada, apenas um artigo foi encontrado.

Isto indica que esta constatação está relacionada com a existência de políticas públicas que incentivam o uso de tecnologias, especialmente dos dispositivos móveis, como é o caso do Projeto UCA e o Projeto Banda Larga nas Escolas. Ambos os projetos foram postos em práticas a partir do ano de 2007, com o ProInfo Integrado. De acordo com Almeida e Valente (2016), no projeto UCA "foram distribuídos cerca de 150.000 laptops, para 350 escolas públicas estaduais e municipais, urbanas e rurais, sendo que cada escola não deveria exceder 500 alunos e professores.” Na sequência, o Projeto Banda Larga nas Escolas veio com o objetivo de conectar à internet todas as instituições públicas do país.

Entretanto, alguns impasses ainda existem, pois muitas escolas acabam 

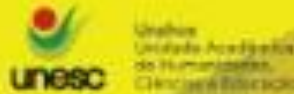

unesc

enfrentando problemas relacionados aos tablets e laptops que não funcionam e à falta de acesso à internet de qualidade, como citado anteriormente. Além disso, permeia a carência de formação continuada dos profissionais da educação, pois muitos desses tablets e laptops acabam engavetados nas escolas, sem utilização, tornando apenas um recurso pedagógico sem significados, contrariando a quinta competência da BNCC, já citada nesta pesquisa.

\subsection{Conteúdos trabalhados por meio dos dispositivos móveis}

A partir das análises dos artigos, pode-se reconhecer que a utilização das tecnologias móveis nos processos educativos ocorreu de uma forma disciplinar, pois os artigos que responderam a este critério trabalharam disciplinas e conteúdos específicos. Dessa maneira, obtiveram-se pesquisas nas disciplinas de química, ciências e português. Nessa sequência, os conteúdos abordados foram respectivamente: funções orgânicas oxigenadas, meio ambiente, reino animal e vegetal, e, por fim, alfabetização e leitura.

Contudo, no artigo de Gomes (2013), que retrata as potencialidades e limites pedagógicos na utilização dos dispositivos móveis na educação de jovens e adultos, evidenciou-se trabalhos por meio de projetos com tema astronomia. Gomes (2013) afirma "[...] que os projetos de trabalho contribuem para a utilização do telefone celular como ferramenta pedagógica, considerando a disponibilidade, envolvimento e flexibilidade da comunidade escolar." Portanto, os projetos na EJA têm o propósito de trazer uma aprendizagem significativa a esses sujeitos, pois cada problemática transpassa o cotidiano destes estudantes, e possivelmente, os tornarão indivíduos ativos no processo de construção do conhecimento.

Os trabalhos por projetos, com a integração de diferentes disciplinas e com uso das novas tecnologias, é uma das mudanças da Base Nacional Comum Curricular (BNCC), de acordo com TIC Educação (CGI.br, 2016). Portanto, espera-se que, não muito distante, práticas interdisciplinares com uso das tecnologias móveis com fins pedagógicos se tornem mais comum em espaços escolares. 


\section{SABERES PEDAGÓGICOS}

Revista do Curso de Graduaçăo de Pedagogia - Unesc

ISSN 2526-4559

\subsection{Dispositivos móveis, aplicativos e programas}

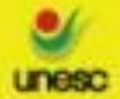

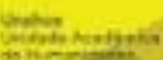

Nesta sessão serão expostos a partir dos artigos analisados, quais foram os dispositivos móveis mais utilizados para as práticas de ensino e aprendizagem em espaços escolares. Além disso, quais os aplicativos e programas foram responsáveis para este processo. Desse modo, identificou-se que em quatro artigos foram relatados o uso de smartphones, três foram tablets, dois laptops e apenas um aparelho celular. Isto certifica que os smartphones são os dispositivos mais utilizados em contexto escolar, uma vez que, atualmente, é a tecnologia móvel mais presente na vida de muitas pessoas, o que vai ao encontro das pesquisas já mencionadas no referencial teórico deste trabalho.

Nessa ordem, o segundo aparelho móvel mais manipulado de acordo com as análises, foram os tablets. Este dispositivo é muito comum nas instituições de ensino, especialmente nas públicas, devido a projetos, como, um computador por aluno-UCA. O projeto em questão não distribui somente tablets, mas também laptops, sendo este último criticado no artigo analisado, em que apresenta as tecnologias móveis na inclusão escolar e digital de estudantes com transtornos de espectro autista.

Nele, o laptop foi considerado uma tecnologia móvel não amigável para crianças com determinados tipos de deficiência por consequência da complexidade do sistema operacional. Além disto, há reprovação em relação à tela, teclado e mouse. Entretanto, os tablets foram classificados como dispositivos de fácil manuseio por conta do toque na tela com os dedos. Ainda, segundo Santarosa e Conforto (2015, p. 363), “a arquitetura dessa tecnologia permite seu uso em diferentes lugares e posições, uma resposta positiva para a hiperatividade e para qualificar estratégias de mediação pedagógica."

Tendo em vista os aplicativos e programas, identificou-se após as análises que, na educação infantil e nos anos iniciais do ensino fundamental, aplicativos de jogos digitais foram os mais recorrentes nas práticas pedagógicas. Entre eles, destacam-se o Eduquito, jogos de peças, jogos de dominós, FRUIT NINJA, jogos de labirinto, quebra-cabeça e jogo de basquete. De acordo com (VIGOTSKI 1984 apud MULLER, 2015, p. 8), o interesse pelos jogos em geral é considerado “[...] uma característica dessa faixa etária que ajuda a compreender o desenvolvimento psíquico infantil."

Saberes Pedagógicos, Criciúma, v. 3, n², julho/dezembro 2019.- Curso de Pedagogia - UNESC 

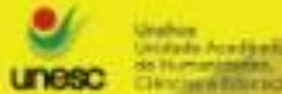

Além dos jogos, alguns artigos recorreram a aplicativos educacionais como ED

Puzzle e Programa de Alfabetização em Língua Materna - PALMA. Destaca-se, ainda, um artigo que utilizou o aplicativo Whatsapp e Google Drive, com a finalidade de promover trabalhos colaborativos. Finalmente, um dos aspectos interessantes e relevante é que programas sem a necessidade de instalação em aparelhos celulares e smartphones como: câmera, gravador de voz e bluetooth também foram utilizados nos processos de ensino e aprendizagem. Portanto, o professor tem inúmeras possibilidades pedagógicas com essas tecnologias, tanto de aplicativos educacionais, quanto de ferramentas e programas já existentes neles.

\subsection{Contribuições pedagógicas e os dispositivos móveis nos processos educativos}

Em todos os artigos analisados, as contribuições pedagógicas por meio das tecnologias móveis foram expostas. Vale ressaltar que, em cada nível de ensino, as tecnologias foram inseridas com objetivos e propósitos diferenciados, levandos-se em consideração as especificidades dos alunos. Dentre as contribuições, destacam-se a construção de habilidades e atitudes, interesse dos alunos por conteúdos curriculares, quebra de barreira entre professores e alunos, criatividade ao usar os dispositivo móveis, aumento do trabalho colaborativo e da criticidade dos fatos.

Além disso, no artigo que retrata a utilização das tecnologias móveis na educação infantil em específico, a autora Muller (2014) destaca que tecnologias nessa faixa etária têm o propósito de trabalhar as diferentes linguagens de forma lúdica. Ainda, de acordo com a autora, a criança, ao interagir com os dispositivos móveis por meio de brincadeiras e jogos com objetivos intencionais, está propensa ao estímulo da imaginação, ao desenvolvimento da fala, dos gestos, do movimento corporal, entre outras linguagens. Ademais, a criança tem a possibilidade de expressão e compreensão da realidade atual.

No artigo que trata da utilização dos dispositivos na educação de jovens e adultos, na disciplina de física, a autora relatou ganhos em relação à mobilidade. Conforme Kenski (2012), essas tecnologias estendem o processo de ensino e aprendizagem para além do contexto escolar. Além disso, verificou-se maior autonomia e interação entre os indivíduos.

Saberes Pedagógicos, Criciúma, v. 3, n², julho/dezembro 2019.- Curso de Pedagogia - UNESC 
Por fim, as tecnologias móveis forneceram a possibilidade do letramento digital, tanto do professor, quanto dos estudantes.

O artigo analisado, de Dias, Deus e Ireland (2013), procurou apresentar a contribuição do uso dos dispositivos móveis para uma educação transformadora na EJA. Nesse sentido, por meio de um aplicativo chamado Programa de Alfabetização em Língua Materna - PALMA, que, de acordo com os autores, “[...] é um software proprietário que tem por proposta auxiliar o processo de aprendizagem da leitura por meio de atividades interativas disponibilizadas em smartphones" (DIAS; DEUS; IRELAND 2013, p. 282), demonstrou que a utilização do aplicativo possibilitou ao educando uma aproximação com a lecto-escrita, em virtude da realização de atividades interativas.

Por fim, o artigo de Santarosa e Conforto (2015), que trata das tecnologias móveis na Educação Especial, salientou que a utilização da tecnologia adequada, no caso de crianças com transtornos de Espectro Autista, foi o tablet, o qual auxiliou a desenvolver a coordenação, comunicação verbal e não verbal. Além disso, auxilia a criança a se tornar autônoma, obedecer a algumas regras, visto que, e um aplicativo de jogos existem regras e elas precisam ser cumpridas para o usuário passar de fase. E, finalmente, no artigo há a ideia que a criança com autismo é capaz de realizar, com auxílio dos tablets, a identificação de formas geométricas, bem como participar do processo de alfabetização.

\subsection{Papel do professor frente ao uso pedagógico dos dispositivos móveis}

Neste tópico será discutido o papel do docente em relação ao uso dos dispositivos móveis nos processos de ensino e aprendizagem. Nessa sequência, dos sete artigos coletados, apenas três responderam com efetividade a este critério. Desses, todos destacaram a importância do professor na introdução de tecnologias móveis nos processos educativos.

O artigo analisado de Dias, Deus e Ireland (2013), enfatiza que somente os recursos tecnológicos não são suficientes para entender a realidade da educação de jovens e adultos. Nesse sentido, surge a importância do papel dos professores, pois eles são capazes não só de incluir digitalmente esses alunos, mas também de torná-los sujeitos críticos perante a sociedade. Em concordância, Mercado (2002, p. 10) afirma, "o professor, neste contexto de 


\section{SABERES PEDAGÓGICOS}

Revista do Curso de Graduaçăo de Pedagogia - Unesc

ISSN 2526-4559

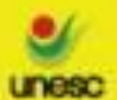

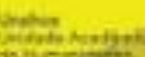

unesc

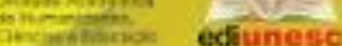

mudança, precisa saber orientar os educandos sobre onde colher a informação, como tratá-la e como utilizá-la." Dessa forma, o educador deve focar também no indivíduo e não apenas nas tecnologias como uma ferramenta.

No artigo de Nascimento e Castro Filho (2016), a professora utilizava o smartphone de fato para fins pedagógicos, visando a aprendizagem. Os autores destacaram, ainda, que o mais importante nas práticas colaborativas utilizando as tecnologias móveis não foi o tablet e nem smartphone, mas sim, a maneira como a professora mediava o processo educativo com os alunos.

No artigo de Gomes (2013), a autora ressaltou que o professor deve ser um mediador do conhecimento e que precisa acreditar que a inserção das tecnologias nas experiências de aprendizagem é positiva. Desta forma, Gomes (2013, p. 18) cita que "para tanto, precisam buscar se letrar digitalmente, (re)significando sua prática docente.” Dessa maneira, entende-se que os professores necessitam de uma formação continuada.

Contudo, de acordo com Mercado (2002), a formação continuada de professores para esta realidade tecnológica ainda é precária, sem apoio de políticas públicas e nem de universidades. Porém, segundo Almeida e Valente (2016), por intermédio do ProInfo Integrado, cursos de extensão foram criados e oferecidos pelas Secretarias de Educação e núcleos de tecnologia educacional de estados e municípios. Estes cursos são destinados à formação de professores e acontecem até nos dias de hoje.

\section{CONCLUSÃO}

Por todas as experiências expostas nesta pesquisa, pode-se concluir que a aplicação das tecnologias móveis vem propiciar inúmeras possibilidades nas práticas de ensino e aprendizagem em espaços escolares. A partir das análises, identificou-se que os dispositivos móveis podem ser inseridos desde a educação infantil e permear até a educação de jovens e adultos, especificamente na EJA e no ensino médio, que foram os níveis que se destacaram em relação à quantidade de pesquisas. Além disso, verificou-se que a maioria dos artigos coletados e analisados eram de escolas públicas, pois pelo fato de existirem políticas 

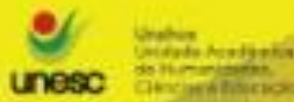

que incentivam o uso de tecnologias móveis, como o UCA, as escolas acabam recebendo a oportunidade de incluírem esses dispositivos em sala de aula.

Foi possível reconhecer que as experiências de ensino e aprendizagem com uso dos dispositivos móveis aconteceram de forma disciplinar, exceto em um artigo que citou trabalhos por projetos com apoio das tecnologias. Ainda, os aparelhos móveis mais utilizados nas experiências foram os smartphones, o que vai ao encontro das pesquisas realizadas nos últimos anos que afirmaram a preferência pelo dispositivo sem fio por sua acessibilidade. Nesse sentido, como recurso pedagógico nas práticas educativas, destacaram-se os aplicativos de jogos e os educativos, o que tornam a aprendizagem mais divertida e prazerosa.

Em consideração às contribuições pedagógicas, as análises demonstraram que em cada nível de ensino as contribuições com o uso das tecnologias móveis vão ser de acordo com o objetivo do professor. Desta forma, cabe ressaltar aqui que a formação continuada dos profissionais da educação precisa ser refletida. Este é um dos pontos principais deste estudo. O professor bem preparado é o fator mais importante nesse processo, pois a partir dele emergem as contribuições pedagógicas, uma vez que ele deverá planejar qual o dispositivo, aplicativo/programa, disciplina/conteúdo e nível de ensino deverá recorrer para atingir tais objetivos.

Finalmente, pretende-se dar continuidade a esta pesquisa, pois entende-se que este trabalho pode contribuir para um campo relativamente novo na educação. Ademais, as tecnologias estão cada vez mais presentes na vida de todos os sujeitos e isso também se reflete no ambiente escolar e consequentemente, nos métodos de ensino e aprendizagem.

\section{REFERÊNCIAS:}

ALMEIDA, Maria Elizabeth Bianconcini; VALENTE, José Armando. Políticas de tecnologia na educação brasileira: histórico, lições aprendidas e recomendações. Estudos 4 Centro de Inovação para a Educação Brasileira (CIEB). Novembro 2016. Disponível em:<http://www.cieb.net.br/wp-content/uploads/2016/12/CIEB-Estudos-4- Políticas-deTecnologia-na-Educacao-Brasileira.pdf>. Acesso em: 24 set 2018.

ASSIS, Patricia Seefelder; SILVA, Fátima Maria Francisca Machado. Educação e tecnologias móveis: um caminho para sabedoria digital. CIET: EnPED, [S.1.], maio 2018. ISSN 2316- 


\section{SABERES PEDAGÓGICOS}

Revista do Curso de Graduaçāo de Pedagogia - Unesc

ISSN 2526-4559

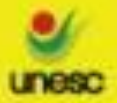

thising

8722. Disponível

em:<http://cietenped.ufscar.br/submissao/index.php/2018/article/view/694/225>. Acesso em: 07 out 2018.

BEHRENS, Marilda Aparecida. Projetos de aprendizagem colaborativa num paradigma emergente. In: MORAN, José Manuel; MASETTO, Marcos T.; BEHRENS, Marilda Aparecida. Novas tecnologias e mediação pedagógica. 10. ed. Campinas, SP: Papirus, 2000.

BRASIL. Ministério da Educação. Secretaria da Educação Básica. Base nacional comum curricular. Brasília, DF, p. 9, 2017. Disponível em:<

http://basenacionalcomum.mec.gov.br/wp-

content/uploads/2018/04/BNCC_EnsinoMedio_embaixa_site.pdf >. Acesso em: 02 maio 2018.

Ministério da Educação. Secretaria da Educação Básica. ProInfo integrado.

Disponível em: < http://portal.mec.gov.br/observatorio-da-educacao/271-programas-e-acoes1921564125/seed-1182001145/13156-proinfo-integrado>. Acesso em: 04 set. 2018.

BLANCO, Elias; SILVA, Bento. Tecnologia educativa em Portugal: conceito, origens, evolução, áreas de intervenção e investigação. Revista Portuguesa de Educação, Braga, p.37-55, 1993. Disponível

em:<http://repositorium.sdum.uminho.pt/bitstream/1822/521/1/1993\%2c6\%283\%29\%2c37-

56\%28EliasBlanco\%26BentoDuartedaSilva\%29.pdf>. Acesso em: 05 jun. 2018.

CANTO, Josi Zanette. Dispositivos móveis: aprender e ensinar com a integração das tecnologias digitais. In: II Simpósio Ibero-Americano de Tecnologias Educacionais. Rexlab (UFSC), Araranguá, [2018]. Disponível em:<http://sited.ufsc.br/others/oficina_dispositivos_moveis.pdf>. Acesso em: 02 maio 2018.

CASTELLS, Manuel. A sociedade em rede. São Paulo: Paz e Terra, 2003.

CETIC. TIC educação: Pesquisa Sobre o Uso das Tecnologias de Informação e Comunicação nas Escolas Brasileiras-2016. São Paulo: CGI, 2017. Disponível em: $\langle$ https://www.cetic.br/media/docs/publicacoes/2/TIC_EDU_2016_LivroEletronico.pdf $>$. Acesso em: 04 set 2018.

DIAS, Daniele dos Santos Ferreira; DEUS, Milene Maria Machado de; IRELAND, Timothy Denis. A contribuição do uso dos dispositivos móveis para um currículo voltado a uma educação transformadora na EJA. Espaço do Currículo, Paraíba, p.280-291, 2013.

Disponível em:<http://www.periodicos.ufpb.br/ojs2/index.php/rec/article/view/17150/9765>. Acesso em: 07 out 2018.

DIAS, Eduardo Jesus; ARAUJO JUNIOR, Carlos Fernando. Mobile learning no ensino de matemática: um framework conceitual para uso dos tablets na educação física. Cruzeiro do

Saberes Pedagógicos, Criciúma, v. 3, n², julho/dezembro 2019.- Curso de Pedagogia - UNESC 


\section{SABERES PEDAGÓGICOS}

Revista do Curso de Graduaçāo de Pedagogia - Unesc

ISSN 2526-4559

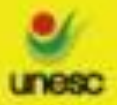

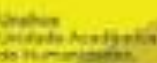

Sul, São Paulo, p.1-13, 2012. Disponível em:<

revistapos.cruzeirodosul.edu.br/index.php/epd/article/download/485/406

>. Acesso em: 15 ago 2018.

DIAS, Rosilãna Aparecida. Tecnologias móveis. [s.d]. Disponível em <https://www.webartigos.com/artigos/tecnologias-moveis/21311>. Acesso em: $20 \mathrm{de}$ set 2018.

ESPÍNDOLA, Rafaela. Como funciona o mobile learning. Atualizado em 16 ago. 2016. Disponível em:< https://www.edools.com/mobile-learning/>. Acesso em: 25 set 2018.

FREIRE, Paulo. Pedagogia do oprimido. Rio de Janeiro: Paz e Terra, 2005.

FUNDAÇÃO TELEFÔNICA VIVO. Juventude conectada 2. 1. ed. - São Paulo: Fundação Telefônica Vivo, 2016. Disponível em:<http://fundacaotelefonica.org.br/wpcontent/uploads/pdfs/Juventude-Conectada-2016.pdf>. Acesso em: 20 set. 2018.

GIACOMAZZO, Graziela Fatima; FIUZA, Patricia. Jantsch. A implantação do tablet educacional na perspectiva dos professores. Revista Tecnologias na Educação, v. 11, p. 110, 2014. Disponível em:<http://tecedu.pro.br/wp-content/uploads/2015/07/Art1-ano6-vol11dez-2014.pdf>. Acesso em: 29 out 2018.

GIL, Antônio Carlos. Como elaborar projetos de pesquisa. 4. ed. São Paulo: Atlas, 2002.

GOMES, Fabíola Anita. Romêro. Potencialidades e limites pedagógicos na utilização dos dispositivos móveis na educação de jovens e Adultos. In: Simpósio Hipertexto e

Tecnologias na Educação, 5, 2013, Recife. Anais eletrônicos. Recife: Universidade Federal de Pernambuco, 2013. p. 1-21. Disponível em: < http://nehte.com.br/simposio/anais/AnaisHipertexto-

2013/POTENCIALIDADES\%20E\%20LIMITES\%20PEDAG\%C3\%93GICOS\%20NA\%20U TILIZA\%C3\%87\%C3\%83O\%20DOS\%20DISPOSITIVOS\%20M\%C3\%93VEIS\%20NA\%2 0EDUCA\%C3\%87\%C3\%830\%20DE\%20JOVENS\%20E\%20ADULTOS.pdf >. Acesso em: 06 out 2018 .

G1. Parlamento Francês aprova proibição dos celulares em escolas na França. Portal G1. Atualizado em 31 de jul. 2018. Disponível em:<https://g1.globo.com/educacao/noticia/2018/07/31/parlamento-frances-aprova-proibicaodos-celulares-em-escolas-na-franca.ghtml>. Acesso em: 24 set 2018.

IBGE. Pesquisa nacional por amostra de domicílios contínua (Pnad C). Estatísticas Sociais, 2018. Disponível em: <https://agenciadenoticias.ibge.gov.br/agencia-sala-de-imprensa/2013-agencia-denoticias/releases/20073-pnad-continua-tic-2016-94-2-das-pessoas-que-utilizaram-a-internet-o-fizerampara-trocar-mensagens>. Acesso em: 01 maio 2018.

KENSKI, Vani. Moreira. Tecnologias e ensino presencial e à distância. Campinas: Papirus,

Saberes Pedagógicos, Criciúma, v. 3, n², julho/dezembro 2019.- Curso de Pedagogia - UNESC 


\section{SABERES PEDAGÓGICOS}

Revista do Curso de Graduaçāo de Pedagogia - Unesc

ISSN 2526-4559

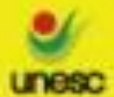

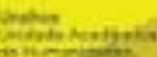

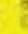

2003.

2012.

Educação e tecnologias: o novo ritmo da informação. $8^{\mathrm{a}}$ ed. Campinas, SP: Papirus,

LEMOS, André. Cibercidades: um modelo de inteligência coletiva. In: LEMOS, André (Org).

Cibercidade: as cidades na cibercultura. Rio de Janeiro: E-papers Serviços Editoriais,

2004, p. 1-5. Disponível em:〈https://facom.ufba.br/ciberpesquisa/andrelemos/modelo.pdf >.

Acesso em: 21 set. 2018.

Cultura da mobilidade. Famecos. Porto Alegre-RS, n. 40, dezembro de 2009. p. 28-

35. Disponível

em: $<$ http://revistaseletronicas.pucrs.br/ojs/index.php/revistafamecos/article/viewFile/6314/45

89>. Acesso em: 21 set 2018.

LIMA, João Paulo Cardoso de et al. Impactos e Barreiras na implantação da

experimentação remota em escolas públicas. Universidade Federal de Santa Catarina-

UFSC, Araranguá, p.1-5, 2014. Disponível em:<

http://recipp.ipp.pt/bitstream/10400.22/9560/1/COM_GustavoAlves_2014_5.pdf >. Acesso

em: 05 out 2018.

LOMBARDI, Evandro; GITAHY, Raquel Rosan Christino. O uso das tecnologias móveis na educação: uma experiência com o ed puzzle. Capes/prosup, Presidente Prudente-SP, p.590594, 2017. Disponível em:<

http://www.unoeste.br/site/enepe/2017/suplementos/area/Humanarum/4\%20-

$\% 20$ Educa\% $\% 3 \%$ A7\%C3\%A3o/O\%20USO $\% 20$ DAS\%20TECNOLOGIAS\%20M\%C3\%93V

EIS\%20NA\%20EDUCA\%C3\%87\%C3\%830\%20UMA\%20EXPERI\%C3\%8ANCIA\%20CO M\%20O\%20ED\%20PUZZLE_.pdf>. Acesso em: 05 out 2018.

MATTAR, Fauze Najeb. Pesquisa de marketing: metodologia, planejamento. 6. ed. São Paulo: Atlas, 2005. v.1.

MORAIS, Philippi Sedir Grilo de et al. Utilização de dispositivos móveis na educação à distância. Disponível em:

$<$ http://arquivos.info.ufrn.br/arquivos/20110111269b2f595062c9c114fa6ea3/1869-5887-1PB.pdf>. Acesso em: 16 maio 2018.

MORAN, José Manuel. Ensino e aprendizagem inovadores com tecnologias audiovisuais e telemáticas. In: MORAN, José Manuel; MASETTO, Marcos T.; BEHRENS, Marilda Aparecida. Novas tecnologias e mediação pedagógica. $10^{\mathrm{a}}$. Ed. Campinas, SP: Papirus, 2000.

MERCADO, Luís Paulo Leopoldo. Novas tecnologias na educação: reflexões sobre a prática. Maceió: EDUFAL, p. 210, 2002.

Saberes Pedagógicos, Criciúma, v. 3, n², julho/dezembro 2019.- Curso de Pedagogia - UNESC 
MERIJE, Wagner. Mobimento: educação e comunicação mobile. São Paulo: Petrópolis, 2012.

MULLER, Juliana Costa. Crianças na contemporaneidade: entre representações e usos das tecnologias móveis na educação infantil. Santa Catarina, 2014. Dissertação. Universidade Federal de Santa Catarina. Disponível em:<https://repositorio.ufsc.br/bitstream/handle/123456789/132433/332936.pdf?sequence=1 \&isAllowed=y $>$. Acesso em: 25 set 2018.

Jogos e brincadeiras com o uso das tecnologias móveis na educação infantil: o que as crianças têm a nos dizer? Reunião Nacional da Anped, Florianópolis, p.1-17, 2015. Disponível em:<http://37reuniao.anped.org.br/wp-content/uploads/2015/02/Trabalho-GT074367.pdf>. Acesso em 23 set 2018.

NASCIMENTO, Karla Angélica Silva. Mc-Learning: Práticas colaborativas na escola com o suporte da tecnologia móvel. 2016. 256 f. Tese - Curso de Educação Brasileira, Universidade Federal do Ceará, Fortaleza, 2016. Disponível em:

<http://www.repositorio.ufc.br/bitstream/riufc/21227/1/2016_tese_kasnascimento.pdf >. Acesso em: 01 maio 2018.

NASCIMENTO, Karla Angélica Silva do; CASTRO FILHO, José Aires de. Dispositivos móveis na educação: ensinando e aprendendo em diferentes contextos. In: CONGRESSO BRASILEIRO DE INFORMÁTICA NA EDUCAÇÃO, 5. 2016, Uberlândia. Anais do XXVII Simpósio Brasileiro de Informática na Educação. S.1: Congresso Brasileiro de Informática na Educação, 2016. p. 1 - 10.. Disponível em: <http://www.brie.org/pub/index.php/sbie/article/viewFile/6812/4697>. Acesso em: 11 out 2018.

OLIVEIRA, Leandro Ramos de; MEDINA, Roseclea Duarte. Desenvolvimento de objetos de aprendizagem para dispositivos móveis: uma nova abordagem que contribui para a educação. Novas tecnologias na educação, CINTED/UFRGS, RS, p. 01-11, 01 jul. 2007. Disponível em: <http://www.cinted.ufrgs.br/ciclo9/artigos/4aLeandro.pdf >. Acesso em: 01 maio 2018.

PINHEIRO, José Maurício dos Santos. Da iniciação científica ao TCC: uma abordagem para os cursos de tecnologia. Rio de Janeiro: Ciência Moderna, 2010, p. 161.

ROCHADEL, Willian; AQUINO, Ellen Larissa de Carvalho; SILVA, Juarez Bento. Desenvolvimento de aplicação para interfaceamento com experimentos remotos por smarthphones. RENOTE, p. 02-10, 01 jul. 2012. Disponível em:< www.seer.ufrgs.br/renote/article/download/30793/19195>. Acesso em: 01 maio 2018.

SANTA CATARINA. Lei ${ }^{\circ} 14.363$, de 25 de janeiro de 2008. Dispõe sobre a proibição do uso de telefone celular nas escolas estaduais do Estado de Santa Catarina. Florianópolis, SC, 25 jan 2008. Disponível em:< http://leis.alesc.sc.gov.br/html/2008/14363_2008_lei.html>. Acesso em: 11 out 2018.

Saberes Pedagógicos, Criciúma, v. 3, n², julho/dezembro 2019.- Curso de Pedagogia - UNESC 
SANTAROSA, Lucila Maria Costi; CONFORTO, Débora. Tecnologias móveis na inclusão escolar e digital de estudantes com transtornos de espectro autista. Rev. bras. educ. espec., Marília, v. 21, n. 4, p. 349-366, Dec. 2015. Disponível em: $<$ http://www.scielo.br/scielo.php?script=sci_arttext\&pid=S141365382015000400349\&lng=en\&nrm=iso>. Acesso em: 13 out 2018.

UNESCO. Organização das nações unidas para a educação, a ciência e a cultura - UNESCO. Diretrizes de políticas da UNESCO para a aprendizagem móvel. Trad. Rita Brossard. Setor de educação da representação da UNESCO no Brasil. Brasília: UNESCO, 2014. Disponível em:<http://unesdoc.unesco.org/images/0022/002277/227770por.pdf >. Acesso em: 22 set 2018 .

ZUIN, Vânia Gomes; ZUIN, Antônio Álvaro Soares. O celular na escola e o fim pedagógico. Educ. Soc., Campinas, v. 39, n. 143, p. 419-435, jun. 2018. Disponível em:<http://www.scielo.br/pdf/es/v39n143/1678-4626-es-39-143-419.pdf >. Acesso em: 09 out 2018. 